\title{
Representações da identidade docente: uma contribuição para a formulação de políticas"
}

口 Alda Judith Alves-Mazzotti* *

\section{Resumo}

Este artigo focaliza uma pesquisa que teve por objetivo identificar as representações da identidade docente construídas por professores da rede pública de ensino fundamental do Rio de Janeiro frente aos desafios postos à escola na contemporaneidade. Optou-se pela abordagem estrutural das representações proposta por Abric. Os dados foram coletados por meio de um teste de associação de palavras com justificativa e tratados utilizando o software EVOC. Participaram do estudo 248 professores, 123 de $1^{a}$ a $4^{a}$ série e 125 de $5^{a}$ a $8^{a}$. Os resultados indicaram diferenças significativas entre as representações dos dois grupos, refletidas nas configurações de seus núcleos centrais: no $1^{\circ}$. grupo $\left(1^{a}\right.$ a $4^{a}$ série) o núcleo é constituído por um único elemento - dedicação -, embora na periferia próxima apareça o termo cansativo; e no $2^{\circ}$. ( $5^{a}$ a $8^{a}$ série), são destacados os termos dificuldades e luta. Concluiu-se que os professores de $1^{a}$ a $4^{a}$ série parecem atribuir à sua identidade um sentido tradicionalmente associado à função docente, enquanto para os de $5^{a}$ a $8^{a}$, ser professor hoje é lutar cotidianamente contra as inúmeras dificuldades que se interpõem entre ele e seus alunos.

Palavras-chave: Representações sociais. Identidade do professor. Trabalho docente.

\section{Abstract \\ Representations of teachers' identity: a contribution for policy making}

This paper focus on a research aimed at identifying the representations of the professional identity of teachers of public schools of Rio de Janeiro in face of the challenges posed to the schools in contemporary times. We adopted the structural approach of the social representations proposed by Abric. Data were collected using a free association test with justification and treated by the software EVOC. The participants of the study were 248 subjects, from which 123 teachers of $7^{\text {st }}$ to $4^{\text {th }}$ grade and 125 of $5^{\text {th }}$ to $8^{\text {th }}$ grade. Results indicated significant differences between the representations of the two groups, reflected in the configurations of their central nuclei: In the first group, the nucleus is comprised by a single element - dedication -, although in the close periphery, the term tiresome appears. As to the second group, the terms difficulties and struggle, are distinguished as components of the central nucleus. It was concluded that the

"Este artigo é parte de uma pesquisa apoiada pelo CNPq

"* Doutora em Psicologia da Educação; Professora do PPGE da Universidade Estácio de Sá. E-mail: aldamazzotti@uol.com.br 
teachers of the first grades construct the meaning of being a teacher today around a nucleus traditionally associated to the teaching role, while for those of the $5^{\text {th }}$ to $8^{\text {th }}$, being a teacher today is to struggle daily against the several difficulties that lie between them and their students.

Keywords: Social representations. Teacher identity. Teacher's work.

\section{Resumen}

\section{Representaciones de la identidad docente: una contribución para la formulación de políticas educativas}

El artículo presenta una investigación cuyo objetivo es identificar las representaciones sociales de la identidad profesional de los maestros de las escuelas públicas de Río de Janeiro frente a los desafíos contemporáneos que la educación les presenta. Se ha adaptado el modelo estructural de representación social propuesto por Abric. Los datos se han recogido usando un tes de asociación libre y se han tratado mediante el sofware EVOC. Han participado en el estudio 248 maestros, 123 de $1^{\circ}$ a $4^{\circ}$ grados y 125 de $5^{\circ}$ a $8^{\circ}$ grados. Los resultados indicaran diferencias significativas entre las representaciones de los dos grupos reflectadas en sus núcleos centrales. En el primer grupo el núcleo está constituido por un elemento simple-dedicación- y en la periferia aparece el término cansancio. En el segundo grupo destacan los términos dificultad y lucha como componentes del núcleo central. Se concluye que los maestros de $7^{\circ}$ a $4^{\circ}$ grados construyen su identidad actual alrededor de un núcleo tradicionalmente asociado con el rol del profesor; mientras que para los profesores de $5^{\circ}$ a $8^{\circ}$ grados, ser maestro hoy es luchar cotidianamente contra las muchas dificultades que aparecen entre ellos y los alumnos.

Palabras clave: Representaciones sociales. Identidad del maestro. Trabajo docente.

A preocupação com a identidade profissional do professor e a natureza do trabalho docente têm sido objeto de inúmeros estudos nos últimos anos (ESTEVE, 1995; KUENZER, 1999; LUDKE; BOING, 2004, NÓVOA, 1995; PERRENOUD, 2000; PIMENTA, 1996; SAMPAIO; MARIN, 2004; SARTI, 1997 ; RICCI, 1999; TARDIF; LESSARD, 2005). Tais estudos buscam, por diferentes caminhos, ressignificar o trabalho do professor com vistas a proporcionar uma formação que o capacite a enfrentar os desafios postos à escola na contemporaneidade.

Os desafios não são poucos. $\bigcirc$ mundo contemporâneo vem sendo marcado por rápidas e profundas transformações decorrentes do processo de globalização, exigindo que o sujeito seja capaz de lidar com a crescente integração das economias nacionais e as novas exigências de qualificação do trabalhador, que trazem consigo o desemprego, ampliando as distâncias sociais e intensificando os processos de exclusão. Deste cenário complexo, fazem parte a crise da ética, o esvaziamento das funções tradicionais da família, o esgarçamento dos laços de solidariedade, a incerteza quanto ao futuro e a violência presente no cotidiano das grandes cidades As novas tecnologias de informação e comunicação constituem outro aspecto significativo da cultura contemporânea, propiciando aos alunos novas formas de conhecer e de se relacionar, as quais, se por um lado abrem novas pers- 
pectivas à educação, por outro exigem dos professores o domínio de novas mídias com as quais poucos deles estão familiarizados.

Esses desafios encontram um professor fragilizado pelo desprestígio da profissão e pela crescente precarização de seu trabalho. Em sua análise do trabalho docente, Tardif e Lessard (2005) associam esse processo à massificação do ensino que, na América do Norte e nos países europeus, se inicia após a segunda guerra mundial. Esses autores afirmam que a organização escolar tem sido historicamente concebida, tanto em sua forma como no conteúdo, em estreita relação com os modelos organizacionais do trabalho produtivo e a normatização das condutas que sustentam a racionalização das sociedades modernas. Assim, à medida que a escola vaise abrindo a um número cada vez maior $\mathrm{e}$ mais diversificado de alunos - os quais, supõe-se, devem atingir resultados semelhantes ao final de sua trajetória escolar - vão sendo introduzidos mecanismos burocráticos de padronização e controle do trabalho do professor, pautados em modelos de gestão e normas de execução utilizados nas empresas. Esses autores sustentam que, por desconhecerem as especificidades do trabalho docente, esses mecanismos, longe de profissionalizarem o ensino, levam à proletarização do trabalho do professor, transformando-o em mero executor de decisões tomadas em outras instâncias. Em outras palavras, objetivase o trabalho do professor, o que tem repercussões negativas na qualidade do ensino, em sua adaptabilidade às diferenças de estilos de ensinar e de aprender, e na própria identidade do professor.

Todos os desafios apontados põem em cheque as funções clássicas da escola e o papel do professor, levando governos e pesquisadores do campo da educação a propor novas metas para a escola e a procurar "gestar uma nova identidade do profissional docente" (PIMENTA, 1996, p. 73) capaz de lidar com as demandas da realidade contemporânea de forma crítica e afinada com os ideais democráticos de formação dos alunos para o exercício da cidadania e inserção digna no mundo do trabalho. A efetivação das mudanças desejadas implica saber em que medida elas se aproximam da representação do professor sobre sua identidade profissional hoje.

Concordamos com Perrenoud (1999), quando afirma que a realidade educativa não se transforma apenas pela adoção de boas idéias, mas sim pela mudança das representações, atitudes, valores e da própria identidade dos atores. Nesse sentido, o conhecimento das representações sociais do professor - como um conjunto organizado de julgamentos, atitudes e informações elaborados a respeito de um objeto social com o objetivo de orientar e justificar práticasassume relevância para orientar políticas voltadas para a formação inicial e continuada do professor.

Assim, a pesquisa aqui relatada teve por objetivo identificar as representações sociais da "identidade profissional docente" de professores da rede pública de ensino fundamental do Município de Rio de Janeiro, frente aos desafios postos à escola na contemporaneidade.

\section{A abordagem estrutural}

A abordagem estrutural das representações proposta por Abric (1994a, 1994b, 1996, 1998, 2003) foi adotada por se considerar que é a mais adequada quando o interesse do estudo está relacionado a uma possível intervenção nas práticas. Segundo Abric, só há mudança efetiva na representação quando o núcleo central é alterado. 
A idéia essencial de Abric é a de que toda representação está organizada em torno de um núcleo central (NC) que determina, ao mesmo tempo, sua significação e sua organização interna. Este núcleo, por sua vez, é diretamente determinado pela natureza do objeto representado, pelo tipo de relações que o grupo mantém com o objeto e, principalmente pelo sistema de valores e normas sociais que constituem o contexto ideológico do grupo, o qual é marcado por condições históricas e sociais e vinculado à memória coletiva. O NC constitui a base comum da representação, sendo indispensável a sua identificação para que se possa avaliar a homogeneidade de um grupo. Dito de outra forma, só podemos afirmar que dois ou mais grupos têm a mesma representação de um objeto se estes partilharem o mesmo $\mathrm{NC}$; não basta que as representações apresentem os mesmos elementos; se os NCs forem diferentes, elas serão diferentes.

NC desempenha três funções essenciais: (a) uma função geradora - ele é o elemento pelo qual se cria e se transforma uma representação; (b) uma função organizadora - é ele que determina a natureza das ligações entre os elementos de uma representação; e (c) uma função estabilizadora - seus elementos são os que mais resistem à mudança. (ABRIC, 1994a, 1994b, 2003).

As várias técnicas que têm sido desenvolvidas para a identificação dos elementos do NC procuram levar em conta as três características que permitem distingüi-los dos outros elementos da representação: valor simbólico, poder associativo e saliência. A primeira se refere ao fato de que estas mantêm com o objeto uma relação necessária, "não negociável". Isto quer dizer que, na visão do grupo considerado, elas não podem ser dissociadas do objeto da representação sob pena de este perder toda a significação. Po- der associativo diz respeito à polissemia das noções centrais e à sua capacidade de se associarem aos outros elementos da representação, uma vez que elas condensam o conjunto de significações. A saliência está diretamente relacionada às duas características anteriores: graças ao seu valor simbólico e à sua polissemia, as cognições centrais ocupam um lugar privilegiado no discurso, sendo evocadas mais freqüentemente que as demais (MOLINER, 1994). No entanto, Abric (1994a, 1994b, 2003) esclarece que a dimensão quantitativa não é, por si só, determinante da centralidade de um elemento; há também que considerar sua dimensão qualitativa, isto é, se este elemento é ou não aquele que dá sentido à representação. Isto torna necessário o teste da centralidade, o qual se baseia justamente na verificação do caráter inegociável dos elementos mais salientes.

Os outros elementos que entram na composição da representação, os chamados de elementos periféricos (EP), constituem a parte operatória da representação, desempenhando um papel essencial no funcionamento e na dinâmica das representações. Abric (2003) destaca cinco funções do sistema periférico no funcionamento e dinâmica das representações: (a) concretização do NC em termos ancorados na realidade, imediatamente compreensíveis e transmissíveis; (b) regulação, que consiste na adaptação da representação às transformações do contexto, integrando novos elementos ou modificando outros em função de situações concretas com as quais o grupo é confrontado, (c) prescrição de comportamentos: os EP funcionam como esquemas organizados pelo NC, garantindo o funcionamento instantâneo da representação como grade de leitura de uma dada situação e, conseqüentemente, orientando tomadas de posição; (d) proteção do NC: o sistema periférico é um elemento essencial nos mecanismos de defesa que 
visam a proteger a significação central da representação, absorvendo as informações novas suscetíveis de pôr em questão o NC; e (e) modulações personalizadas: é o sistema periférico que permite a elaboração de representações individualizadas relacionadas à história e experiências pessoais do sujeito.

Flament (1994) ressalta a importância do sistema periférico ou, como ele chama, da "periferia", uma vez que é através da periferia que as representações aparecem no cotidiano, o funcionamento do núcleo central (NC) não pode ser compreendido senão em uma dialética contínua com os aspectos periféricos. Afirma, ainda, que é por comparação com um elemento periférico de igual saliência que um elemento central é definido, e é por contraste com a condicionalidade periférica que os elementos incondicionais aparecem como "não negociáveis", e portanto, como pertencentes ao NC. Lembra, finalmente que uma transformação, mesmo pequena do NC, é preparada longamente na periferia.

\section{Aspectos metodológicos}

A pesquisa foi realizada em 15 escolas públicas de ensino fundamental do Rio de Janeiro. Os resultados aqui apresentados tomaram por base um teste de livre evocação de palavras, com justificativa, conforme o proposto por diversos autores (ABRIC, 1994b; FLAMENT, 1981; TURA, 1998).

Participaram desta etapa 248 professores do ensino fundamental, sendo 123 do primeiro segmento ( $1^{a}$ a $4^{a}$ séries) e 125 do segundo $\left(5^{a}\right.$ a $\left.8^{a}\right)$. $\bigcirc$ primeiro subgrupo incluía 114 mulheres e 9 homens, e o segundo, 98 mulheres e 27 homens. $\bigcirc$ tempo de exercício de magistério variou entre 3 anos e 20 anos ou mais, sendo que esta última faixa foi a que concentrou maior número de sujeitos, em ambos os segmentos. Quanto ao nível de escolaridade, no primeiro segmento $22 \%$ dos professores só têm nível médio, e, no segundo segmento, todos têm curso superior.

$\bigcirc$ teste de livre evocação consistiu em solicitar ao sujeito que escrevesse as quatro primeiras palavras que the ocorressem ao ouvir a expressão indutora: ser professor, hoje. A seguir, pedia-se que indicasse as duas palavras mais importantes, dentre as que escrevera, ordenando-as. Finalmente, solicitava-se que justificasse, em um pequeno texto, a importância atribuída a estas palavras. $O$ tratamento do teste foi realizado com o auxílio do software EVOC (VERGÉS, 1994), que identifica os possíveis elementos do núcleo central considerando a freqüência (F) e a ordem média de evocação $(\mathrm{OME})^{1}$. Os resultados são distribuídos em dois eixos ortogonais com as palavras de maior frequência e menor OME situadas no quadrante superior esquerdo, correspondente ao NC. As que se situam no quadrante superior direito constituem a "periferia próxima" ao NC; no quadrante inferior direito, que pode ser considerado a "periferia propriamente dita", aparecem os elementos de menor freqüência e evocação mais tardia; já o quadrante inferior esquerdo, por força da ambigüidade de suas coordenadas (menor freqüência e evocação mais próxima à dos elementos do NC), é de mais interpretação menos precisa (FLAMENT, 1994).

Para completar a análise da estrutura, buscou-se identificar a organização dos elementos da representação, utilizando-se a análise de similitude das categorias defini-

\footnotetext{
${ }^{1}$ A freqüência $(F)$ de uma evocação é o somatório de suas freqüências nas diversas posições; a freqüência média (FM) é a média aritmética das diversas freqüências obtidas por uma evocação. A ordem média de uma evocação (OME) é calculada pela média ponderada obtida mediante a atribuição de pesos diferenciados à ordem com que, em cada caso, uma dada evocação é enunciada.
} 
das na análise das evocações. Esta técnica, baseada na teoria dos grafos, permite verificar o poder associativo dos elementos do núcleo e os demais, por meio do exame da árvore máxima, aquela cuja soma das arestas é a maior dentre as encontradas em todas as árvores possíveis (TURA, 1998). Finalmente, foi feita a verificação da centrali- dade $^{2}$ de cada um dos possíveis componentes do núcleo central, utilizando-se como recurso a dupla negação (CAMPOS, 1998).

\section{Resultados}

O Quadro 1 apresenta a possível estrutura da representação social do ser professor hoje para os professores do primeiro segmento.

\begin{tabular}{|c|c|c|c|c|c|c|}
\hline & Evocação & $f_{x}$ & $\mathrm{OME}<2,7$ & Evocação & $f_{x}$ & OME $\geq 2,7$ \\
\hline$f_{x} \geq 25$ & Dedicação & 35 & 2,143 & Cansativo & 27 & 2,741 \\
\hline \multirow{8}{*}{$\begin{array}{l}7>f \\
<15\end{array}$} & Dificuldades & 22 & 1,727 & Amor & 20 & 2,800 \\
\hline & Desafio & 15 & 1,533 & Ter paciência & 17 & 3,294 \\
\hline & Amigo & 11 & 2,455 & Muita responsabilidade & 15 & 2,733 \\
\hline & Gosta do que faz & 9 & 1,778 & Aprendizagem & 11 & 2,818 \\
\hline & Gratificante & 9 & 1,889 & Carinho & 9 & 2,667 \\
\hline & Vocação & 9 & 2,333 & Alegria & 8 & 3,000 \\
\hline & Luta & 8 & 1,875 & Esperança & 8 & 3,750 \\
\hline & Persistência & 8 & 2,250 & & & \\
\hline
\end{tabular}

Quadro 1 - Possível composição do Núcleo Central do Sistema Periférico para Professores do Primeiro Segmento do Ensino Fundamental.

Fonte: Mazzotti (2007).

Observa-se que no núcleo central destaca-se uma única palavra, dedicação, indicando uma representação tradicional, arraigada à história e à cultura docente, com seus valores, modelos e crenças. Esse núcleo, como vimos, gera os sentidos e organiza as relações dos elementos que compõem o sistema periférico. Assim, podemos observar que os termos que se apresentam na periferia propriamente dita (amor, ter paciência, muita responsabilidade, aprendizagem, carinho, alegria e esperança) remetem a uma realidade idealizada, com uma ênfase no socialmente desejável que se coaduna com o sentido de dedicação. No entanto, na periferia próxima, com forte tendência à centralidade, aparece o termo cansativo, o que sugere que talvez a representação esteja sofrendo uma transição.

A Árvore Máxima de Similitude, ao indicar a organização e o poder associativo dos elementos da representação, ajuda a compreender melhor os sentidos dos termos dedicação e cansativo. Esses elementos formam figuras abertas (arestas soltas e cadeias ou seqüências de arestas) ou se conectam, formando figuras fechadas ou ciclos (triângulos, quadriláteros, etc.). A força do vínculo entre diferentes elementos é indicada pela espessura das arestas.

\footnotetext{
${ }^{2}$ A um grupo 30 de sujeitos (15 de cada grupo), apresentou-se por escrito, a seguinte proposição: "Para cada uma das frases abaixo, assinale a opção que the parecer mais adequada." A seguir, eram apresentadas frases envolvendo cada uma das evocações mais destacadas pelos respondentes: "Não se pode pensar em ser professor (a palavra indutora) sem pensar em Y (evocação)." Abaixo de cada frase vinham as opções "não, não se pode"; "sim, se pode"; e "não sei dizer", cabendo ao sujeito assinalar a que melhor the parecesse em cada caso.
} 


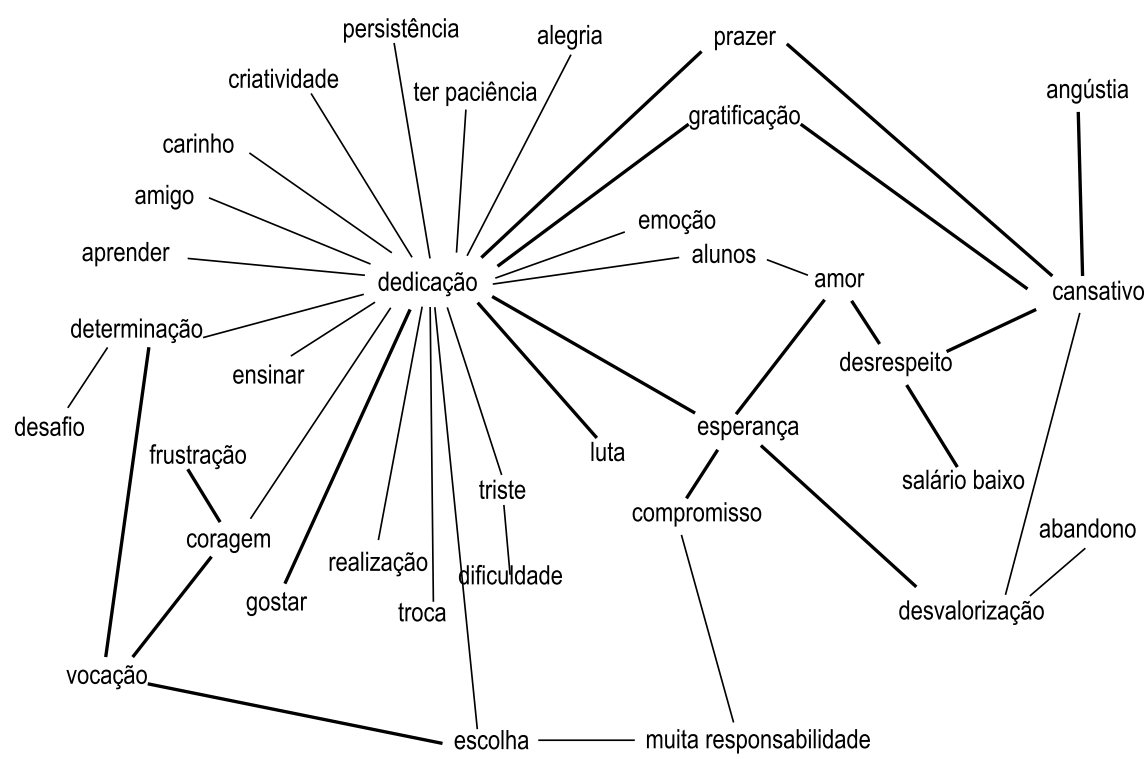

Figura 1 - Árvore Máxima de Similitude do Primeiro Segmento do Ensino Fundamental

A Árvore Máxima de Similitude ${ }^{3}$ confirma o termo dedicação como o de maior poder associativo com 21 arestas. A maior parte delas (13), porém, não constitui cadeias nem ciclos, o que mostra, ao mesmo tempo, a variedade de noções, valores, sugerindo que se trata de clichês, sem muito significado para os sujeitos. Note-se, ainda, que dedicação e cansativo, termos mais destacados nas evocações, situam-se em vértices opostos, ilustrando uma ambivalência entre os elementos constitutivos da representação, cujos indícios podem ser observados em todo o campo.

Quanto à análise das figuras é possível constatar a formação de dois quadriláteros: (a) dedicação, determinação, vocação, coragem, dedicação e (b) dedicação, determinação, vocação, escolha, dedicação. Estes conjuntos indicam sentidos implicados na definição do núcleo central, os quais são coerentes com as justificativas analisadas.
A estas figuras, acrescenta-se o pentágono formado pelas arestas que ligam os seguintes pontos: (c) dedicação, escolha, muita responsabilidade, compromisso, esperança, dedicação. Ao juntarmos as figuras (a), (b) e (c) podemos entrever uma modulação nos sentidos associados ao termo dedicação: um espaço definido como uma escolha, demarcada pelo compromisso, e a esperança, do qual a alegria, a troca, a emoção, a realização, a criatividade e, mesmo, a luta, são arestas que se conectam à dedicação e só a ela. Cabe assinalar que, das arestas ligadas a dedicação, os elementos gostar, prazer, gratificação, esperança e luta são aqueles cuja associação com aquele elemento é mais forte, sendo que gostar e luta se vinculam somente à dedicação, o que significa que só foram mencionados relacionados àquele elemento.

${ }^{3}$ Uso do negrito indica que os termos estão fortemente associados (ver Árvore [...] $1^{\circ}$ segmento). 
Tal configuração sugere que dedicação se sustenta em sentidos altamente valorizados. No entanto, esse elemento, através de prazer e gratificação, apresenta uma forte associação com cansativo (periferia próxima). Este último termo, por sua vez, constitui o centro de uma figura com 5 arestas: as que o ligam a (d) desvalorização, desrespeito, gratificação, prazer e angústia. Fundado no termo cansativo, tem-se também um quadrilátero, unindo (e) prazer, dedicação, gratificação e cansativo e, finamente, um pentágono formado pelas arestas que se unem em ( $f$ ) cansativo, desrespeito, amor, esperança, desvalorização, cansativo.

É interessante assinalar, ainda, que através de (g) esperança, configura-se outro pentágono que liga desvalorização, cansativo, prazer, dedicação e esperança e um quadrilátero, articulando (h) amor, alunos, dedicação e esperança. Este é o único caso no qual o termo "alunos" aparece, e o faz em um contexto positivo, cujos elementos são tão coerentes que formam como que uma frase.

A análise das justificativas apresentadas permitiu perceber que o termo dedicação está associado à vocação, missão, doação, como indicam as que se seguem:

"porque ser professor é passar a viver também a vida de seus alunos, orientado-os e ajudando-os a entender melhor a vida;"

"o professor deve pensar, sentir e respirar a problemática do grupo;"

"porque é preciso se dar à profissão, amar o que faz;"

"todo professor tem que ter o "dom", a vocação, a entrega de si;"

"ser professor toca a mais profunda devoção porque o professor se doa em prol de ideais nobres;" "é o professor se doar como um todo, sem pensar em dinheiro."

Com esses sentidos, a dedicação é naturalizada como algo intrínseco a essa profissão:

"nenhum professor exerce sua profissão sem ela;"

"faz parte do trabalho, pois lidamos com crianças;"

"a profissão e doação em todos os sentidos;"

"para fazer um bom trabalho é preciso dedicação;"

"profissionalismo + responsabilidade $=$ dedicação;"

"apesar de tudo que o professor passa, ele não pode deixar de se dedicar"

precisamos, senão desistimos."

Quanto ao cansaço, as falas seguintes expressam seus sentidos:

"apesar de gostar do que faço, é desgastante pelos diversos problemas que encontramos;"

"muitos anos de profissão, vida atribulada e a engrenagem da educação não me dão esperança;"

"é desgastante pela falta de apoio, principalmente da família."

Concluindo, a análise das justificativas apresentadas pelos professores do primeiro segmento para a associação do termo "dedicação" à profissão docente, parece indicar uma tendência à "blindagem" de uma identidade positiva através de mecanismos de defesa, como a negação dos efeitos dos aspectos negativos da profissão sobre a identidade profissional; ou 
a racionalização, por meio de frases feitas e lugares comuns inseridos em um discurso racional. A este sentido idealizado da profissão, fundado em valores, modelos, símbolos e estereótipos tradicionais, a realidade da prática atual vem opondo outro, que prenuncia uma transformação da representação de ser professor repre- sentada pela tendência à centralidade do termo cansativo.

Os resultados referentes à possível estrutura das representações sociais do ser professor hoje, para os professores do segundo segmento do ensino fundamental $\left(5^{a}\right.$ a $\left.8^{a}\right)$ são apresentados no Quadro 2.

\begin{tabular}{|c|c|c|c|c|c|c|}
\hline & Evocação & $f_{x}$ & $\mathrm{OME}<2,7$ & Evocação & $f_{x}$ & OME $\geq 2,7$ \\
\hline \multirow[t]{2}{*}{$f_{x} \geq 24$} & Dificuldades & 35 & 1,714 & Amor & 26 & 2,769 \\
\hline & Luta & 35 & 2.424 & Desgastante & 31 & 2,774 \\
\hline \multirow{6}{*}{$\begin{array}{l}>10 f_{x} \\
<24\end{array}$} & Correria & 13 & 2,077 & Caos & 13 & 3,077 \\
\hline & Decepção & 13 & 2,538 & Desvalorização & 10 & 2,900 \\
\hline & Desafio & 10 & 2,500 & Profissionalismo & 10 & 3,300 \\
\hline & Frustração & 16 & 2,500 & & & \\
\hline & Salário baixo & 13 & 2,692 & & & \\
\hline & Ter paciência & 22 & 2,373 & & & \\
\hline
\end{tabular}

Quadro 2 - Possível composição do Núcleo Central do Sistema Periférico para Professores do Segundo Segmento do Ensino Fundamental. Fonte: Mazzotti (2007).

Como se observa no Quadro 2, dificuldades e luta são os possíveis componentes do núcleo central. Na periferia próxima, verifica-se a presença de amor e desgastante, dois termos que sugerem ambivalência. Esta ambivalência, no entanto, se desfaz ao se examinarem as justificativas relacionadas à evocação do termo amor, em comparação àquelas vinculadas à palavra desgastante: no primeiro caso, são em geral muito vagas ou slogans vazios, como, por exemplo, "o amor é a base de tudo na vida", "o amor ao próximo", sugerindo estarem orientadas para o socialmente desejável. Desgastante, ao contrário, é coerente com as dificuldades do cotidiano e a luta constante para superálas, apontadas nas justificativas. 


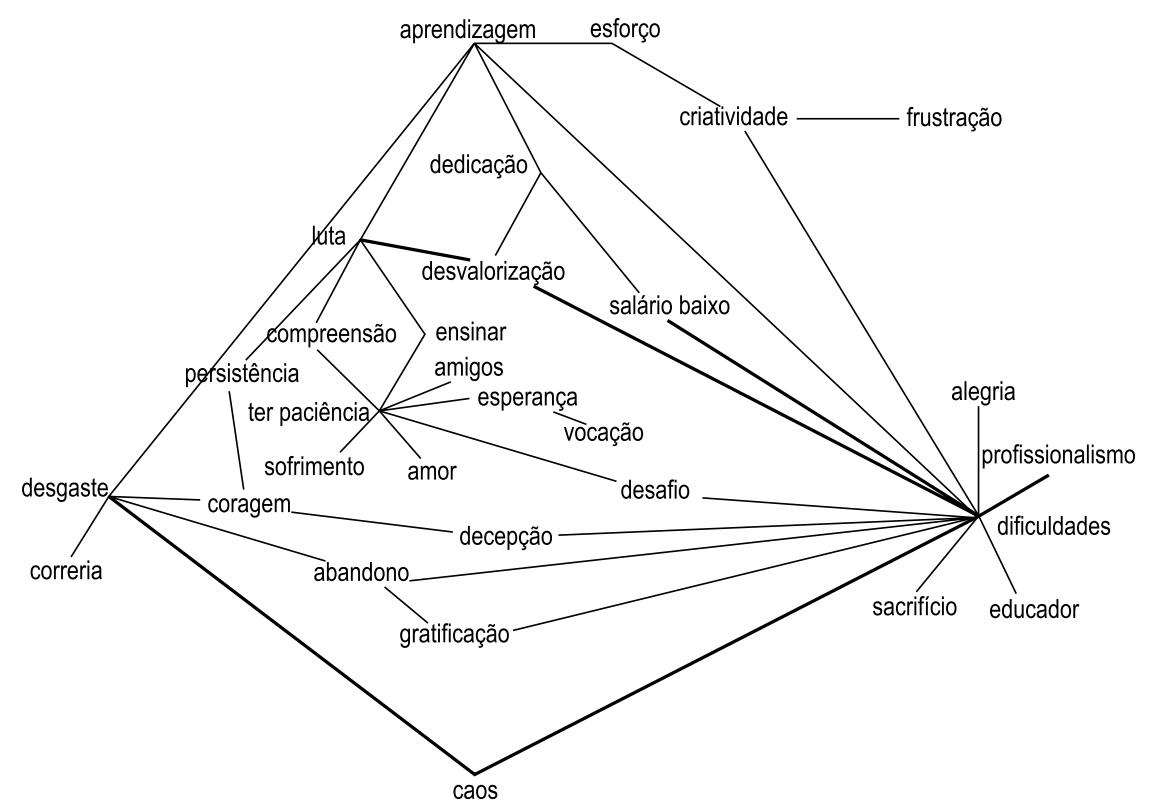

Figura 2 - Árvore Máxima de Similitude do Segundo Segmento do Ensino Fundamental

Em uma primeira análise da Árvore Máxima de Similitude deste segmento podem ser distinguidos três pólos: além de dificuldades (13 arestas) e luta (5 arestas), indicados anteriormente como possíveis componentes do núcleo central, aparece ter paciência (7 arestas). Entretanto, dificuldades e luta são os elementos que apresentam maior poder associativo, uma vez que a eles se associam cadeias e ciclos que concatenam vários sentidos do ser professor. Já com o elemento ter paciência, isto não ocorre: a única figura que a tem como vértice está associada a luta, elemento ao qual se opõe; as outras arestas que a ele se vinculam diretamente, como amigo, esperança, desafio, amor, sofrimento -, não se articulam a outros vértices e expressam sentidos tradicionalmente ligados à função docente, mas que parecem estar perdendo força diante das dificuldades encontradas no cotidiano escolar. $\bigcirc$ conjunto de combinações associadas a difi- culdades e luta, porém, é mais coerente, deixando transparecer uma visão crítica do contexto social mais amplo e do sistema de educação pública do Rio de Janeiro, bem como da situação do professor que nele atua.

Nesta análise, é importante destacar inicialmente que a aresta que liga dificuldades a luta passa por desvalorização, e que esta é uma associação forte. $\bigcirc$ elemento dificuldades dá origem a várias combinações, dentre as quais vale destacar: (a) dificuldades, desvalorização, luta, aprendizagem, dedicação, salário baixo e dificuldades; (b) dificuldades, caos, desgaste, abandono, e dificuldades; (c) dificuldades, decepção, coragem, desgaste, abandono e dificuldades; (d) dificuldades, criatividade, esforço, aprendizagem; e (e) dificuldades, salário baixo, dedicação, aprendizagem, desgaste, coragem, persistência, luta, desvalorização e dificuldades. 
Chama a atenção, nesta Árvore, o pequeno número de arestas conectadas a apenas um pólo, sem se desdobrar em outras associações. Assim, apenas ao pólo dificuldades, estão ligados os elementos alegria, profissionalismo, sacrifício e educador; e conectadas a luta não há arestas soltas. Tais configurações indicam consistência entre os elementos da representação do que é ser professor hoje, uma vez que os sentidos destacados pelos sujeitos, em sua grande maioria, são coerentes e bem articulados entre si. Além disso, o fato de que profissionalismo tem uma ligação forte com dificuldades, e somente com este elemento, indica que, sempre que o primeiro termo apareceu, o fez ligado ao segundo. Isto sugere que, embora o profissionalismo seja uma preocupação, os professores parecem não estar conseguindo vencer os obstáculos encontrados em sua prática cotidiana para que possam se afirmar como profissionais.

A análise das justificativas apresentadas pelos professores do segundo segmento, para a associação dos elementos dificuldades e luta tendo como referente o ser professor hoje, fornece indícios de quais seriam esses obstáculos. As justificativas se referem ao descaso e incompetência dos governos, às condições de trabalho, às exigências das Secretarias, à falta de compromisso dos alunos com a aprendizagem, à desvalorização da profissão, aos baixos salários que levam o professor a trabalhar em várias escolas e às frustrações e desafios que o professor tem que enfrentar em seu cotidiano. As justificativas que se seguem são ilustrativas:

(a) dificuldades

"muita dificuldade, como falta de interesse, de material, de investimentos;"

"há grande dificuldade do material ao emocional. Muitas exigências para pouco resultado efetivo!" "é difícil trabalhar onde existe tanta cobrança e tão pouco interesse dos alunos e pais;"

"o modelo atual de governo só nos traz dificuldades;"

"porque hoje é difícil ser professor com o salário baixo e várias escolas para trabaIhar;"

"agressividade, falta de valores. Essa agressividade se refere à luta pela sobrevivência da sociedade hoje".

(b) luta

"ser professor hoje é tentar passar valores, conceitos que os nossos alunos acham inúteis;"

"em virtude das diferenças sociais, torna-se cada vez mais difícil fazer o aluno interessar-se pela educação;"

"lutar contra o desgaste, o desinteresse, a crise de valores, a violência;"

"temos sempre de alavancar, nós que acreditamos na educação, os projetos pensados para não dar certo e, além disto, suportar e enfrentar os absurdos do governo;"

"o papel do professor é de luta constante contra a desvalorização e as propostas metodológicas ineficientes."

A comparação entre os dados obtidos com os professores do primeiro e do segundo segmentos parece indicar que estes últimos representam o ser professor de uma forma menos idealizada do que os primeiros, uma vez a construção de sentidos do trabaIho docente se ancora mais na vivência cotidiana das dificuldades e da luta para exercer o magistério com profissionalismo do que nos valores agregados à vocação.

Cabe, finalmente, assinalar que o teste da centralidade do NC das representações 
de ser professor obtidos em ambos os grupos de professores confirmou, unanimemente, os elementos dedicação no primeiro segmento e dificuldades e luta no segundo.

\section{Considerações finais}

De acordo com Abric (1998, p. 31), "para que duas representações sejam diferentes, elas devem ser organizadas em torno de dois núcleos centrais diferentes". Podemos, portanto, concluir que os professores de $1^{a}$ a $4^{a}$ e os de $5^{a}$ a $8^{a}$ têm representações diferentes sobre o que é do ser professor hoje. Abric nos indica, ainda, que os elementos do núcleo central são consensuais, ligados à memória coletiva e à história do grupo e se caracterizam por apresentarem grande resistência à mudança (ABRIC, 1994a).

A longa duração do elemento dedicação, que compõe o núcleo da representação dos professores do primeiro segmento, é atestada por vários estudos. Araújo (1998), com base na análise dos escritos educacionais de Erasmo, Montaigne e Rabelais, mostra que, desde o século XVI, a dedicação é relacionada ao perfil do professor. Também no Brasil dedicação é um elemento tradicionalmente atribuído à função docente, como indicam, por exemplo, pesquisas realizadas por Martins, (1998) e Oliveira (1998). Esta última autora destaca, na representação de professores sobre o trabalho docente, algumas características do mito, encontradas também em nosso estudo: a ênfase na vocação inata, hereditária e a tendência à doação e ao sofrimento. Compara a representação trabalho do professor ao mito de Sísifo, símbolo do trabalho infindável e sem sentido, o que guarda estreita semelhança com o sentido de cansativo, destacado em nosso estudo.

A pesquisa de Oliveira (1998) também nos dá pistas sobre a historicidade e consensualidade dos elementos dificuldades e luta, que constituem o núcleo da representação construída pelos professores do segundo segmento. Essa autora mostra que a imagem do herói que não se deixa abater pelas dificuldades, lutando incessantemente para superá-las e "mudar o mundo" é também bastante arcaica e conclui que um complexo representacional de cunho defensivo leva os professores a considerar seu trabalho como um "ato heróico".

Entre as dificuldades encontradas para o exercício da profissão são enfatizados pelos professores de ambos os segmentos: o acúmulo de tarefas atribuídas ao professor, as condições de trabalho desfavoráveis; a perda de autonomia, a degradação dos salários, e a falta de tempo livre para planejar aulas mais atraentes e para o desenvolvimento profissional e pessoal. Esses professores consideram que as novas tarefas representam um desvio de suas funções essenciais, depreciando ainda sua imagem pública, que acreditam ser a pior possível. Todos esses fatores, que têm sido associados à precarização do trabalho docente, estão vivamente descritos no discurso de professores de ambos os grupos e na periferia de suas representações.

Mas, se as dificuldades apontadas pelos professores dos dois segmentos são tão semelhantes, o que, então, os distingue?

Parece-nos que é a tomada de posição diante dessas dificuldades: se os professores de $1^{a}$ a $4^{a}$ a elas respondem com dedicação, os de $5^{a}$ a $8^{a}$ a elas opõem a luta. Nesse sentido, estes dois grupos se situam em pólos opostos no se que refere ao objeto "ser professor".

Esta interpretação está de acordo com características essenciais do núcleo central. Segundo Abric (2003, p. 41), o núcleo de uma representação é constituído por elemen- 
tos normativos, decorrentes do sistema de valores dos indivíduos e responsáveis pelas tomadas de posição frente ao objeto; e elementos funcionais, "associados às características descritivas e à inscrição do objeto nas práticas sociais". Esses elementos são acionados de forma diferenciada segundo a natureza do objeto, o tipo de relação que o grupo mantém com o objeto e a finalidade da situação. As situações com forte carga ideológica ou afetiva (como é, sem dúvida, o caso em pauta), ativam elementos marcadamente normativos (CAMPOS, 2003), os quais parecem ter orientado as tomadas de posição presentes nos núcleos centrais dos dois grupos.

Finalmente, o corpus da pesquisa parece indicar que a desvalorização do professor afeta mais profundamente a identidade profissional dos professores de $1^{a}$ a $4^{a}$ que os de $5^{a}$ a $8^{a}$. Maurice, citado por Ludke e Boing (2004), após extensa revisão de estudos sobre o tema, afirma que o único critério consensual para caracterizar uma profissão é a especialização do saber de seus profissionais. As falas dos professores de $5^{a}$ a $8^{a}$ sugerem que estes parecem se respaldar no campo de saber das disciplinas que lecionam, o que, ao mesmo tempo, Ihes permite vincular sua identidade profissional a um grupo de referência mais valorizado (os matemáticos, os historiadores, etc.), escapando, assim, à desvalorização do magistério, algo que os de $1^{a}$ a $4^{a}$ não podem fazer. Também ao contrário dos professores do segundo segmento, os de $1^{a}$ a $4^{a}$ se sentem obrigados a assumir funções que consideram ser da família, o que, para eles, equivale a um esvaziamento da função docente. $E$, por fim, mas não menos importante, são eles os mais responsabilizados pelo fracasso escolar, uma vez que não dividem a docência com outros colegas, como é o caso dos professores do $2^{\circ}$ segmento. Talvez por estas razões seu discurso seja mais defensivo. 


\section{Referências}

ABRIC, J. C. A abordagem estrutural das representações sociais. In: MOREIRA, A. S. P.; OLIVEIRA, D. C. (Org.). Estudos interdisciplinares em representações sociais. Goiânia: AB Ed., 1998.

Abordagem estrutural das representações sociais: desenvolvimentos recentes. In: CAMPOS, P. H. F.; LOUREIRO, M. C. S. (Org.). Representações sociais e práticas educativas. Goiânia: Ed. da UCG, 2003.

. De l'importance de représentations sociales dans le problèmes de l'exclusion sociale. In: Erès, 1996. p. 11-18. (Ed.). Exclusion sociale, insertion et prévention. Saint Agne: Editions Méthodologie de recueil des représentations sociales. In:

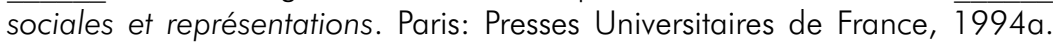

(Ed.). Pratiques

L'organisation interne des représentations sociales: système central et système périphérique. In: GUIMELLI, C. (Ed.). Structures et transformations des répresentations sociales. Lausanne: Delachaux et Niestlé, 1994b. p. 73-84.

ARAÚJO, J. C. S. Representações sociais sobre a profissão docente no século XVI. In: JORNADA INTERNACIONAL SOBRE REPRESENTAÇÕES SOCIAIS, 1., 1998, Natal. Trabalhos apresentados... Natal, RN: [s. n.], 1998.

CAMPOS, P. H. F. As representações sociais de "meninos de rua": proximidade do objeto e diferenças estruturais. In: MOREIRA, A. S. P.; OLIVEIRA, D. C. (Org.). Estudos interdisciplinares em representações sociais. Goiânia: AB Ed., 1998. p. 285-302.

CAMPOS, P. H. F. A abordagem estrutural e o estudo das relações entre práticas e representações sociais. In: CAMPOS, P. H. F.; LOUREIRO, M. C. S. Representações sociais e práticas educativas. Goiânia: Ed. da UCG, 2003. p. 21 - 36.

ESTEVE, J. M. Mudanças sociais e função docente. In: NÓVOA, A. (Org.) Profissão professor. Porto: Porto Ed., 1995.

KUENZER, A. As políticas de formação: a constituição do professor sobrante. Educação \& Sociedade, Campinas, SP, ano 20, n. 68, p. 143-178, dez. 1999.

FLAMENT, C. L'Analyse de similitude: une technique pour les recherches sur les représentations sociales. Cahiers de psychologie cognitive, Marseille, n. 4, p. 357-396, 1981. 
. Aspects périphériques des représentations sociales. In: GUIMELLI, C. (Ed.). Structures et transformations des répresentations sociales. Lausanne: Delachaux et Niestlé, 1994.

GAUTHIER, C. et al. Por uma teoria da pedagogia: pesquisas contemporâneas sobre o saber docente. liuí, RS: Ed. Unijuí, 1998.

LÜDKE, M.; BOING, L. A. Caminhos da profissão e da profissionalidade docente. Educação \& Sociedade, Campinas, SP, v. 25, n. 89, p. 1159-1180, set./dez. 2004.

MARTINS, A. M. S. As representações sobre o ser professor na década de 50. In: JORNADA INTERNACIONAL SOBRE REPRESENTAÇÕES SOCIAIS, 1., 1998, Natal. Trabalhos apresentados... Natal, RN: [s. n.], 1998.

MOLINER, P. Les méthodes de repérage et de identification du noyau des représentations sociales. In: GUIMELLI, C. (Ed.). Structures et transformations des représentations sociales. Neuchâtel: Delachaux et Niestlé, 1994. p. $199-232$.

NÓvOA, A. (Coord.) Profissão professor. Porto: Porto Ed., 1995.

PERRENOUD, P. Construir competências desde a escola. Porto Alegre: Artes Médicas Sul, 1999.

. Dez novas competências para ensinar. Porto Alegre: Artes Médicas Sul, 2000.

OLIVEIRA, E. S. G. Trabalho do professor: trabalho de Sísifo?. Heróicas representações sociais da docência. In: JORNADA INTERNACIONAL SOBRE REPRESENTAÇÕES SOCIAIS, 1., 1998, Natal. Trabalhos apresentados... Natal, RN: [s. n.], 1998.

PIMENTA, S. G. Formação de professores: saberes da docência e identidade do professor. Revista da Faculdade de Educação da USP, São Paulo, v. 22, n. 2, p. 72-89, jul./dez. 1996.

RICCI, R. O perfil do educador para o século XXI: de boi de coice a boi de cambão. Educação \& Sociedade, Campinas, SP, ano 20, n. 66, p. 143-178, abr. 1999.

SAMPAIO, M. M. F.; MARIN, A. J. Precarização do trabalho docente e seus efeitos sobre as práticas curriculares. Educação \& Sociedade, Campinas, SP, v. 25. n. 89, p. 12031225, set./dez. 2004.

SARTI, F. M. Saberes docentes e formação da identidade profissional de futuros professores. In: SIMPÓSIO DE PESQUISA DA FEUSP, 3., 1997, São Paulo. Anais... São Paulo: [s. n.], 1996. (Estudos e Documentos). 
TARDIF, M.; LESSARD, C. O trabalho docente: elementos para uma teoria da docência como profissão de interações humanas. Trad. de João Batista Kreuch. 2. ed. Petrópolis: Vozes, 2005.

TURA, L. F. Aids e estudantes: a estrutura das representações sociais. In: JODELET, D.; MADEIRA, M. C. (Org.). Aids e representações sociais: à busca de sentidos. Natal, RN: EDUFRN, 1998. P. 121-154.

VERGÈS, P. Approche du noyau central: propriétés quantitatives et struturales. . In: GUIMELLI, C. (Ed.). Structures et transformations des représentations sociales. Neuchâtel: Delachaux et Niestlé, 1994. p. 233-254.

Recebido em: 13/09/2007

Aceito para publicação em: 22/10/2007 